\title{
House-dust Mite Asthma. Results of Challenge Tests on Five Criteria with Dermatophagoides pteronyssinus
}

\author{
MONICA K. MCALLEN, ${ }^{*}$ M.D., M.R.C.P. ; E. S. K. ASSEM,† PH.D., M.R.C.P. ; K. MAUNSEI.L, $\ddagger$ M.D.
}

S ummary: Twenty-eight patients with asthma and house-dust allergy were investigated by five different challenge tests with mite extract (Dermatophagoides pteronyssinus). These tests were performed on the skin, bronchi, nasal mucosa, and leucocytes, and on normal human lung tissue passively sensitized by the patients' serum. The results were compared with each other and with the clinical state of the patients.

Of 21 patients on whom all five tests were carried out, positive reactions to every test were found in $14(67 \%)$. Asthmatic attacks were readily induced by inhalation of the mite extract and occurred in $18(86 \%)$. Nasal reactions were provoked in $18(86 \%)$ and were not followed by asthmatic symptoms. A leucocyte test was positive in 19 $(90 \%)$ and the serum test was positive in all $(100 \%)$. Delayed asthmatic responses to bronchial challenge were ieen in six patients, but there was no evidence that these vere mediated by precipitins. Quantitatively there was no fixed pattern between the degrees of sensitivity of the different tissues in the same patient. The amount of mite antigen capable of causing an asthmatic reaction was extremely small-less than $1 \mu \mathrm{g}$. of mite material in several patients.

In view of the prevalence of $D$. pteronyssinus in this country and its high allergenic potency, it is considered that this mite is an important factor in allergic asthma.

\section{Introduction}

The importance of the house-dust mite as a cause of allergic disease has only recently been recognized (Voorhorst et al., 1964, 1967). The mite Dermatophagoides pteronyssinus is found in house dust throughout the world; it is about 0.3 $\mathrm{mm}$. in length and produces faecal pellets which are about the same size as grass pollen grains and are also allergenic. House dust from floors may contain from 1 to 500 of these mites per gramme. Dust from the surfaces of mattresses, however, may contain a great many more, as $D$. pteronyssinus feeds on shed human skin scales which it finds in abundance in bedding (Maunsell et al., 1968). Other mites are found in house dust, but Maunsell et al. found that in England and Wales $D$. pteronyssinus was by far the most common, being present in $82 \%$ of the samples they examined. The highest concentrations of these mites were found in the dust from old damp houses.

We believe that house-dust allergy, promoted by this mite, is the most common cause of allergic asthma in this country, particularly in children. Other workers in this field have expressed similar views (Morrison Smith et al., 1969; Frankland, 1969; Holzel, 1969; Williams, 1969).

Skin tests and challenge tests have been used in the investigation of allergic disease for many years. Positive skin reactions have long been known to be due to the presence in the serum of antibodies known as reagins. Recent work has established that these reagins belong to the newly recognized immunoglobulin class IgE (Bennich et al., 1968).

\footnotetext{
*Consultant Physician, Asthma and Allergy Clinic, University College

Hospital, London W.C.1.
tWellcome Research Fellow, Department of Pharmacology, University College, and Medical Unit, University College Hospital Medical School, London W.C.1.

¥Part-time Clinical Assistant, Department of Medical Microbiology, King's College Hospital, London S.E.
}

Challenge tests are performed by introducing an extract of allergenic material such as pollen directly on to the nasal or bronchial mucosa, thereby inducing an attack of rhinitis or asthma in an allergic subject. In-vitro tests may be made with samples of the allergic patients' leucocytes or serum. Leucocytes are directly challenged with allergenic material, and histamine release is measured (Lichtenstein and Osler, 1964). The patients' serum may be used passively to sensitize isolated normal human lung tissue (Assem and Schild, 1968); the lung tissue is then challenged with the antigen, and the histamine release gives a measure of the reaginic activity of the serum.

Over the past three years routine skin tests with extracts of mites have been made in every new patient attending the asthma clinic of one of us (M.K.McA.). Positive reactions were seen more commonly than with any other allergen, and it was observed that very weak dilutions often provoked large weals. It therefore appeared likely that the quantity of mite antigen which would cause tissue reactions in other "shock organs," such as the nasal mucosa and bronchi, would also be very small, and a series of challenge tests were made to investigate this point. This paper reports the results of these tests and relates them to each other and to the clinical state of the patient.

\section{Selection of Patients}

Twenty-eight patients aged 16 to 60 years with perennial asthma and positive skin reactions to $D$. pteronyssinus were examined. They were a selected group who were able to make frequent outpatient visits, and many of them were therefore living near by in Central London in damp houses with old upholstered furniture. The environment of these patients was therefore well suited to a high mite population. All patients were clinically sensitive to house dust and were suffering from asthma, which resulted in a reduction, during remission, of at least $10 \%$ of their predicted vital capacity or forced expiratory volume in one second (F.E.V.1) and had attacks of wheezing at least once in 24 hours, usually at night. Symptomatic treatment was limited to bronchodilators, used intermittently except in two patients who required steroids. In order not to influence the degree of response bronchodilators were not used within four hours of each challenge test.

\section{Materials and Methods}

Detection and Isolation of Mites.-Live mites may be detected under a low-power binocular microscope, either in house dust or, more easily, in dust brushed off the surface of mattresses. For identification they are transferred to dishes containing $90 \%$ lactic acid at a temperature of 50 to $60^{\circ} \mathrm{C}$.

Culture of Mites.-Cultures were reared by putting several pairs of live mites into Petri dishes containing nine parts of human epidermal scales from electric razor shavings and one part of dried bakers' yeast. They were maintained at $25^{\circ} \mathrm{C}$. and $80 \%$ relative humidity. Subcultures were obtained by adding one part of the old culture to nine parts of fresh medium. I norder to reproduce natural conditions the skin scales were not sterilized. Bacteriological cultures from the skin scales before inoculation with mites grew non-pathogenic bacteria, mainly Staphylococcus albus. 
Preparation of Mite Extracts.-The mite cultures were harvested when they reached a density of about 1,000 mites per $100 \mathrm{mg}$. of culture. Mites were not separated from the medium because the medium becomes highly allergenic from the excretions, and possibly also from the secretions of the mites. The total cultures were defatted with acetone, and the suspension was filtered after 24 hours. The defatted material was then dried and weighed. Ten grammes of this material was then put into $100 \mathrm{ml}$. of normal saline solution containing $0.5 \%$ phenol and left for 24 hours at $4^{\circ} \mathrm{C}$. It was then filtered through a Whatman filter paper No. 4 and sterilized by heating in a water-bath at $100^{\circ} \mathrm{C}$. for 30 minutes. This form of sterilization was preferred to Seitz filtration, which might have transferred filter-passing viruses. Control extracts of skin scales and of dried yeast were prepared in the same way. It was found that there was no loss of skinreacting property of the mite extract after sterilization by heating and that the strength was unimpaired after 12 months' storage at room temperature. Serial dilutions of the extract were made in $0.5 \%$ phenol-saline for challenge testing.

\section{Challenge Tests}

Skin tests were done by the prick method, which has been estimated to introduce one-millionth of a millilitre into the epidermis (Squire, 1950). The size of the diameter of the weal was noted after 15 minutes (these tests were performed on at least two occasions and the mean weal diameters were recorded). Serial dilutions of extract, in tenfold steps from 0.1 $\mu \mathrm{g}$. to $1 \mathrm{mg} . / \mathrm{ml}$. were used, the weakest dilution to produce a weal of more than $1 \mathrm{~mm}$. being taken as the threshold strength.

Nasal challenge tests were performed by spraying the extract directly on to the nasal septum on one side with a coarse spray. Serial strengths from $10 \mu \mathrm{g}$. to $1 \mathrm{mg} . / \mathrm{ml}$. were applied on alternate sides at 10 -minute intervals until a reaction consisting of sneezing, watering, or blocking of the nose occurred. The weakest strength to cause a reaction was noted and the threshold dose was calculated from this and the known output ( $0.02 \mathrm{ml}$. per shot) of the spray.

Bronchial challenge tests were carried out with the closed circuit method (Herxheimer, 1951; McAllen, 1961). An extract of standard strength was introduced into the circuit by means of a nebulizer of very low output, and the dose of the antigen was varied by altering the time of inhalation. A positive immediate reaction consisted of a minimal asthmatic attack $(10-20 \%$ reduction of F.E.V.1 or F.V.C.) coming on 5 to 10 minutes after the end of the inhalation. A positive late reaction consisted of an asthmatic attack starting 4 to 12 hours after the end of the inhalation. The reproducibility of these reactions was checked by further testing at the same level of dosage. Only one test was done on any one day in order to be able to record any late reactions; in fact, the tests were done at weekly intervals. The time of inhalation was five seconds in the first instance, and was increased by doubling the exposure at each subsequent challenge until a positive reaction was obtained. If after seven tests and reaching an exposure time of 320 seconds there had been no reaction, the bronchial response was considered negative. The threshold dose was calculated from the shortest time of exposure which caused a positive reaction, the strength of the extract $(1 \mathrm{mg} . / \mathrm{ml}$.$) , and the output of the nebulizer (0.03 \mathrm{ml} . /$ minute $)$.

Leucocyte challenge tests were carried out by a modification of the method of Lichtenstein and Osler (1964), different concentrations of antigen being used. The maximum histamine release and the concentration of antigen causing this release were recorded. The strengths of mite extract used were from 0.1 to $100 \mu \mathrm{g} . / \mathrm{ml}$. of leucocyte suspension containing 2.5 million leucocytes. The details of these tests are reported elsewhere (Assem and McAllen, 1970).
Reaginic activity of serum was measured by passive sensitization of chopped normal human lung tissue incubated in the allergic patient's serum. Histamine release from the lung tissue was then measured following its challenge with mite extract. This method is described by Assem and Schild (1968). The degree of the response was measured by the amount of histamine released in excess of the control experiments on other samples of the same lung tissue. The strength of the mite extract used for these tests was $50 \mu \mathrm{g} . / \mathrm{ml}$. (Assem and McAllen, 1970).

Examination of Sera for Precipitins to D. pteronyssinus.This test was carried out in all patients, including all those who showed late bronchial reactions or negative leucocyte tests. Immunodiffusion in $1 \%$ agar was carried out by the method of Ouchterlony (1958) but using different concentrations (from $30 \mu \mathrm{g}$. to $10 \mathrm{mg} . / \mathrm{ml}$.) of the mite extract.

\section{Control Experiments}

Skin, nasal, and bronchial challenge tests were performed in all patients with control material. In the case of the skin tests an extract of the culture medium in $0.5 \%$ phenol-saline was used, but in the other tests phenol-saline was used alone. The water-soluble protein content of the extract of the culture medium was $1 \mathrm{mg}$. $/ \mathrm{mg}$. of total solid. For the in-vitro tests aliquots of serum and leucocytes from the first five patients were challenged with an extract of the culture medium. Leucocytes from 10 and serum from six normal non-allergic subjects with negative skin tests were also challenged with the mite extract. Blood was taken for leucocyte and serum tests after one screening skin test and before the in-vivo challenge tests were performed in 10 of the patients (indicated in Table II). In the others the blood was taken after all these tests had been completed.

\section{Results}

The clinical features and qualitative results of the five different challenge tests are shown in Table I. Patients are grouped according to their types of allergic condition. All had perennial rhinitis and asthma, but they differed in respect of the age of onset of asthma, the presence of a history of infantile eczema, and the presence of other positive skin tests as well as to dust.

The first clinical group comprises six patients who had atopic disease in infancy and continued to have asthma. The second group developed symptoms in early childhood but, unlike the first group, did not have eczema; they all had multiple positive skin tests. The third group developed asthmatic symptoms in late childhood or early adult life and were allergic to house dust alone. There were no patients who developed asthma in middle age.

The results show that of the 21 patients who were subjected to all five challenge tests, $14(67 \%)$ yave positive reactions to every test. Eighteen of these 21 patients gave reactions to the bronchial tests $(86 \%)$ and 18 gave reactions to the nasal tests $(86 \%)$, one or the other test being positive in every patient. In the in-vitro tests the reaction rate was even higher. Of the same 21 patients, $19(90 \%)$ gave positive leucocyte reactions and $21(100 \%)$ had positive serum reaginic activity. There was little difference between the results in the three clinical groups, but in those patients who had infantile eczema every challenge test was positive.

Late reactions to the bronchial challenge tests were shown by six patients; they occurred at any time between 4 and 12 hours after the test and were not accompanied by any constitutional symptoms, nor was there any pyrexia or chest pain. The asthmatic symptoms usually lasted for one to two hours, but in two patients (Cases 13 and 19) they persisted for seven days. In none of the patients with late reactions to 
TABLE I.-House-dust Mite Asthma-Comparison of Challenge Tests and Clinical State

\begin{tabular}{|c|c|c|c|c|c|c|c|c|}
\hline \multirow{2}{*}{\multicolumn{2}{|c|}{ Case No. }} & \multirow[b]{2}{*}{ Age } & \multirow{2}{*}{$\begin{array}{l}\text { Resp. } \\
\text { Func. } \\
(\%)\end{array}$} & \multirow[b]{2}{*}{ Skin } & \multicolumn{4}{|c|}{ Challenge Tests } \\
\hline & & & & & Nasal & Bronchial & Leucocyte & $\begin{array}{l}\text { Serum } \\
\text { Reaginic } \\
\text { Activity }\end{array}$ \\
\hline \multicolumn{9}{|c|}{ Onset at Under Age 1 Year + Eczema } \\
\hline $\begin{array}{r}11 \\
8 \\
25\end{array}$ & 列 & $\begin{array}{l}24 \\
33 \\
33 \\
20 \\
36 \\
46\end{array}$ & $\begin{array}{l}75 \\
75 \\
70 \\
90 \\
75 \\
70\end{array}$ & $\begin{array}{l}t \\
t \\
t \\
t \\
t\end{array}$ & $\begin{array}{l} \pm \\
\pm \\
+ \\
\pm \\
+\end{array}$ & $\begin{array}{l}+ \\
+ \\
+ \\
+ \\
+\end{array}$ & $\begin{array}{l}+ \\
+ \\
+ \\
+\end{array}$ & $\begin{array}{c}+ \\
+ \\
+ \\
+ \\
+ \\
\text { N.D. }\end{array}$ \\
\hline
\end{tabular}

\begin{tabular}{rll|r}
20 & $\cdots$ & $\cdots$ & 35 \\
14 & $\cdots$ & $\cdots$ & 2 \\
16 & $\cdots$ & $\cdots$ & 19 \\
9 & $\cdots$ & $\cdots$ & 38 \\
28 & $\cdots$ & $\cdots$ & 3 \\
10 & $\cdots$ & $\cdots$ & 3 \\
26 & $\cdots$ & $\cdots$ & 26 \\
4 & $\cdots$ & $\cdots$ & 2 \\
22 & $\cdots$ & $\cdots$ & 3 \\
21 & $\cdots$ & $\cdots$ & 25
\end{tabular}

Onset at Age 1-10 Years. Multiple Allergies

\begin{tabular}{l|l|l|l|l|l|l}
35 & 85 & + & Neg. & + & + & + \\
22 & 85 & + & + & + & + & + \\
19 & 88 & + & + & + & + & + \\
38 & 90 & + & + & + & + & + \\
30 & 85 & + & + & + L. & + & N.D. \\
30 & 85 & + & + & Neg. & + & N.D. \\
38 & 81 & + & + & Neg. & + & + \\
26 & 78 & + & + & Neg. & + & N.D. \\
22 & 90 & + & + & + & + & + \\
35 & 65 & + & + & N.D. & + & + \\
25 & 83 & + & + & N.D. & Neg. & Neg.
\end{tabular}

12
7
27
2
17
1
6
13
23
3
19

Onset at Age 12-15 Years. Single Allergy

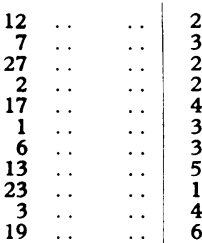

\begin{tabular}{l|l|}
29 & 81 \\
35 & 85 \\
23 & 90 \\
28 & 85 \\
48 & 70 \\
30 & 90 \\
34 & 85 \\
50 & 68 \\
16 & 88 \\
48 & 73 \\
60 & 55
\end{tabular}

81
85
90
85
70
90
85
68
88
73
55

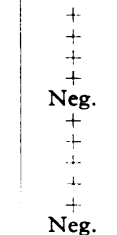

$$
\begin{gathered}
+ \\
+\mathrm{L} . \\
+ \\
+ \\
+\mathrm{L} . \\
\text { Neg. } \\
\text { Neg. } \\
+\mathrm{L} . \\
+\mathrm{L} . \\
+ \\
+\mathrm{L}
\end{gathered}
$$


Resp. Func. $=$ Vital capacity in remission of asthma expressed as a percentage of the predicted normal. L. = Late reaction. N.D. = Not done.

predicted normal. L. $=$ Late reaction. N.D.
Cases 3 and 19 were on systemic steroid treatment.

the inhalation tests were Arthus type skin reactions seen, nor were precipitins to $D$. pteronyssinus found in the serum. The serum was examined for precipitins in every patient, including, of course, all six patients with late bronchial reactions and all three with negative leucocyte tests; precipitins to $D$. pteronyssinus extract were not found in any one.

The degrees of sensitivity measured by the five different challenge tests are shown in Table II. No pattern could be seen whereby the sensitivities of the various "shock organs" were related in the individual patient. The only significant relationship in the quantitative measurements was between the two in-vitro tests. This was shown by the Spierman index of rank correlation, and is discussed elsewhere (Assem and McAllen, 1970).

It can be seen from Table II that the three clinical groups of patients did not show any pronounced differences one from another, both highly sensitive and weakly sensitive reactions occurring in all groups. There was no evidence that a higher bronchial sensitivity was associated with a greater severity of asthma as measured by impairment of respiratory function. It is of interest that the two patients (Cases 3 and 19) who were on steroid treatment had negative leucocyte reactions, whereas the only other patient who had a negative leucocyte response was one with the weakest response to skin tests.

The control experiments on the skin, the nose, and the bronchi were uniformly negative. The in-vitro control experiments on the non-allergic subjects were negative in eight and very weakly positive in two. The serum from the five asthmatic patients which was examined for possible reaginic activity to the culture medium was found to be positive in one (Case 20). The same patient gave a positive leucocyte reaction to the culture medium but the skin test was negative. Control in-vitro tests on all the other mite-sensitive patients were negative.
TABLE II.-House-dust Mite Asthma-Comparison of Quantitative

\begin{tabular}{|c|c|c|c|c|c|c|c|c|}
\hline & & Resp. & Skin 7 & rests & & & & \\
\hline & & $\begin{array}{l}\% \text { of } \\
\text { Pred. } \\
\text { V.C. }\end{array}$ & $\begin{array}{l}\text { Thr. } \\
\text { Conc. } \\
\text { ( } \mu \mathrm{g} . / \\
\text { ml.) }\end{array}$ & \begin{tabular}{|c|} 
Weal \\
Diam. \\
S.S. \\
(mm.) \\
\end{tabular} & $\begin{array}{c}\text { Challenge } \\
\text { Thr. } \\
\text { Dose } \\
\text { ( } \mu \mathrm{g} .)\end{array}$ & $\begin{array}{l}\text { Challenge } \\
\text { Thr. } \\
\text { Dose } \\
\text { ( } \mu \mathrm{g} .)\end{array}$ & $\begin{array}{c}\text { Leucocyte } \\
\text { Challenge } \\
\text { Opt. con c. } \\
(\mu \mathrm{g} . / \mathrm{ml} .)\end{array}$ & $\begin{array}{l}\text { Serum } \\
\text { Reaginic } \\
\text { Activity }\end{array}$ \\
\hline $\begin{array}{c}15^{*} \\
18 \\
5 \\
11 \\
8 \\
25^{\circ} \\
\end{array}$ & $\begin{array}{l}\cdots \\
\cdots\end{array}$ & $\begin{array}{l}75 \\
75 \\
70 \\
90 \\
75 \\
70 \\
\end{array}$ & $\begin{array}{r}1.0 \\
1.0 \\
100.0 \\
100.0 \\
100.0 \\
1.0 \\
\end{array}$ & $\begin{array}{r}6 \\
12 \\
3 \\
9 \\
7 \\
6 \\
\end{array}$ & $\begin{array}{r}2 \cdot 0 \\
0 \cdot 2 \\
2 \cdot 0 \\
2 \cdot 0 \\
20 \cdot 0 \\
60 \cdot 0 \\
\end{array}$ & $\begin{array}{l}7 \cdot 0 \\
0 \cdot 3 \\
1 \cdot 0 \\
8 \cdot 0 \\
4 \cdot 0 \\
1 \cdot 0\end{array}$ & $\begin{array}{r}4 \cdot 0 \\
20 \cdot 0 \\
20 \cdot 0 \\
20 \cdot 0 \\
20 \cdot 0 \\
20 \cdot 0\end{array}$ & $\begin{array}{c}+++ \\
++ \\
++ \\
+++ \\
+ \\
\text { N.D. }\end{array}$ \\
\hline $\begin{array}{l}20^{*} \\
14 \\
16 \\
9 \\
24 \\
28 \\
10^{*} \\
26^{*} \\
4 \\
22^{*} \\
21^{*}\end{array}$ & $\begin{array}{l}\ldots \\
\cdots \\
\cdots \\
\cdots\end{array}$ & $\begin{array}{l}85 \\
85 \\
88 \\
90 \\
85 \\
85 \\
81 \\
78 \\
90 \\
65 \\
83\end{array}$ & $\begin{array}{r}100.0 \\
100.0 \\
100.0 \\
10.0 \\
10.0 \\
10.0 \\
10.0 \\
100 \cdot 0 \\
10.0 \\
100 \cdot 0 \\
1,000 \cdot 0 \\
\end{array}$ & $\begin{array}{r}8 \\
10 \\
8 \\
15 \\
18 \\
7 \\
6 \\
9 \\
5 \\
12 \\
5\end{array}$ & $\begin{array}{l}\text { Neg. } \\
60 \cdot 0 \\
0 \cdot 2 \\
20 \cdot 0 \\
20 \cdot 0 \\
20 \cdot 0 \\
20 \cdot 0 \\
60 \cdot 0 \\
20 \cdot 0 \\
60 \cdot 0 \\
60 \cdot 0 \\
\end{array}$ & $\begin{array}{c}0.05 \\
1.0 \\
2.0 \\
1.5 \\
0 \cdot 1 \\
\text { Neg. } \\
\text { Neg. } \\
2 \cdot 0 \\
1.0 \\
\text { N.D. } \\
\text { N.D. }\end{array}$ & $\begin{array}{r}20 \cdot 0 \\
4 \cdot 0 \\
20 \cdot 0 \\
100 \cdot 0 \\
100 \cdot 0 \\
4 \cdot 0 \\
4 \cdot 0 \\
20 \cdot 0 \\
20 \cdot 0 \\
20 \cdot 0 \\
\text { Neg. }\end{array}$ & $\begin{array}{c}+++ \\
++++ \\
+++ \\
++ \\
\text { N.D. } \\
\text { N.D. } \\
++ \\
\text { N.D. } \\
++++ \\
++ \\
\text { Neg. }\end{array}$ \\
\hline $\begin{array}{c}12 * \\
7 * \\
27 \\
2 \\
17 \\
1 \\
6 * \\
13 \\
23 \\
3 \\
19 \\
\end{array}$ & 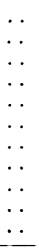 & $\begin{array}{l}81 \\
85 \\
90 \\
85 \\
70 \\
90 \\
85 \\
68 \\
88 \\
73 \\
55 \\
\end{array}$ & $\begin{array}{r}10 \cdot 0 \\
100 \cdot 0 \\
1 \cdot 0 \\
100 \cdot 0 \\
100 \cdot 0 \\
10 \cdot 0 \\
10 \cdot 0 \\
10 \cdot 0 \\
10 \cdot 0 \\
1,000 \cdot 0 \\
10 \cdot 0 \\
\end{array}$ & $\begin{array}{r}12 \\
4 \\
5 \\
8 \\
8 \\
9 \\
8 \\
6 \\
7 \\
4 \\
19 \\
\end{array}$ & $\begin{array}{l}20 \cdot 0 \\
60 \cdot 0 \\
60 \cdot 0 \\
20 \cdot 0 \\
\text { Neg. } \\
20 \cdot 0 \\
20 \cdot 0 \\
20 \cdot 0 \\
20 \cdot 0 \\
60 \cdot 0 \\
\text { Neg. }\end{array}$ & $\begin{array}{r}1.0 \\
1.0 \\
20 \cdot 0 \\
0.4 \\
2.0 \\
\text { Neg. } \\
\text { Neg. } \\
4 \cdot 0 \\
6 \cdot 0 \\
0.5 \\
0.8\end{array}$ & $\begin{array}{r}4 \cdot 0 \\
0 \cdot 1 \\
N . D . \\
100 \cdot 0 \\
20 \cdot 0 \\
4 \cdot 0 \\
4 \cdot 0 \\
20 \cdot 0 \\
4 \cdot 0 \\
\text { Neg. } \\
\text { Neg. }\end{array}$ & $\begin{array}{c}+++ \\
+++ \\
\text { N.D. } \\
+++ \\
+ \\
+++ \\
+++ \\
++ \\
++ \\
+ \\
+\end{array}$ \\
\hline & & & Neg. & Neg. & N.D. & N.D. & $\begin{array}{l}\text { Neg. or } \\
\text { V. weak }\end{array}$ & $\begin{array}{l}\text { Neg. or } \\
\text { v. weak }\end{array}$ \\
\hline
\end{tabular}

*Patients in whom serum and leucocyte tests were done before in-vivo challenge tests Weal Diam. S.S. = Diameter of weal at standard strength $(1 \mathrm{mg} . / \mathrm{ml}$.).

Thr. Conc. $=$ Threshold concentration of extract which produced a positive reaction. Thr. Dose $=$ Threshold amount of solid material which produced a positive reaction.

\section{Discussion}

A different species of the genus Dermatophagoides, $D$. culinae (synonymous with $D$. farinue), which is rarely found in dust samples in this country, has been used by some authors for tests in subjects allergic to house dust. Stenius and Wide (1969) showed that positive skin tests with $D$. culinae extracts were related to IgE antibody in patients with house dust allergy. They and also Pepys et al. (1968) obtained positive nasal and bronchial challenge reactions with $D$. culinae in their patients, but quantitative measurements were not reported. Bronchial challenge tests in Switzerland on 20 patients allergic to house dust were reported by Bachofen et al. (1967). An extract of $D$. pteronyssinus was used and positive reactions were obtained in half the patients. No quantitative measurements of sensitivity were reported.

In the series here reported the results of our challenge tests confirm that $D$. pteronyssinus extract is able to provoke reactions in the nasal mucosa and the bronchi, but, in contrast to the findings of the previous authors, our patients showed positive reactions in a much higher proportion of cases. It has already been stated that the group under study were probably heavily exposed to mites in their home environment. This may well have been a factor in their high sensitivity as compared with the Swiss patients, and the use of $D$. pteronyssinus instead of $D$. culinae might account for the higher proportion of positive reactions we obtained than did Stenius and Wide.

The quantitative results in our patients are mainly of interest in respect of their discrepancies. It is oommon clinical experience that patients with respiratory allergy may be more troubled either by asthma or by rhinitis, and it seems likely that the reactivity thresholds of the lung and the nasal tissues would be different in the same patient. By the same reasoning the size of the skin test reaction would not be expected to be related to the sensitivity of the lung or nasal mucosa. The results of our measurements of threshold reactions confirm these observations. 
Patients with atopic disease since infancy and who had had infantile eczema were found to react readily to all the challenge tests; nevertheless, even in these highly allergic subjects the titres of the positive reactions were no higher than those of other patients.

The possibility that sensitization of some of the patients might have been promoted by the repeated skin, nasal, and bronchial challenge tests has to be considered. The blood samples were therefore taken before the serial in-vivo challenge tests in a random 10 patients. Some of the strongest positive serum and leucocyte reactions were found in these 10 patients, and in only one were the blood tests weak or negative. These findings indicate that sensitization was unlikely to have been promoted by the testing procedures in the rest of the patients.

The negative tests for precipitins suggest that the late bronchial reactions seen in six patients were not mediated by precipitins (as such reactions are in allergic alveolitis) and are not manifestations of Arthus-like type III immune responses in the lung. The mechanism of these late reactions in asthmatic patients has not been established, though such reactions have been described in detail previously and have been estimated to occur in about $30 \%$ of patients with house dust asthma (Herxheimer, 1952; McAllen, 1961). It seems possible that they may be due to cell-mediated immune responses (delayed hypersensitivity).

Perhaps the most significant finding in our experiments is that the actual amount of antigen required to produce a tissue reaction both in vitro and in vivo is so extremely small. This is of the order of 0.05 to $1 \mu \mathrm{g}$. in the bronchi and 0.5 to $20 \mu \mathrm{g}$. in the nose; it would thus be possible under natural conditions for an allergic reaction to be caused by the inhalation of mite material such as faecal pellets or parts of dead mites in an amount weighing less than one whole live mite.

It is concluded that the negative findings in the control tests and the high titres of sensitivity in the challenge tests on the allergic subjects establish that the mite $D$. pteronyssinus contains a very potent antigen. This antigen can cause high levels of reaginic antibody and can stimulate histamine release from leucocytes of sensitized patients when brought into direct contact with them in very weak dilution. It is also able to react with sensitized tissues in the skin, the nasal mucosa, and the bronchi in allergic subjects, and can cause symptoms from inhalation of very small quantities. It would therefore appear likely that the mite $D$. pteronyssinus is an important factor in the causation of perennial allergic asthma in this country.

We wish to thank Mrs. A. M. Briess, Mrs. A. Coombes, Mrs. M. Barker and Miss K. Folkard for technical help.

E.S.K.A. is in receipt of a grant from the Wellcome Trust. The work was supported by grants from the Asthma Research Council.

\section{REFERENCES}

Assem, E. S. K., and McAllen, M. K. (1970). British Medical fournal, 2, 504-507. Assem, E. S. K., and Schild, H. O. (1968). British Medical fournal, 3,

Bachofen, H., Scherrer, M., Träutlein, F., and Wyss, F. (1967) Deutsche Medizinische Wochenschrift, 92, 36, 1597.

Bennich, H., et al. (1968). Immunology, 15, 323.

Frankland, A. W. F. (1969). Personal communication.

Herxheimer, H. (1951). International Archives of Allergy and Applied Immunology, 2, 40 .

Herxheimer, H. (1952). International Archives of Allergy and Applied Immunology, 3, 323 .

Holzel, A. (1969). Personal communication.

Lichtenstein, L. M., and Osler, A. G. (1964). Fournal of Experimental Medicine, 120, 507.

McAllen, M. K. (1961). Thorax, 16, 30.

Maunsell, K., Wraith, D. G., and Cunnington, A. M. (1968). Lancet, 1, 1267.

Ouchterlony, O. (1958). Progress in Allergy, 5, 1.

Pepys, J., Chan, M., and Hargreave, F. E. (1968). Lancet, 1, 1270.

Smith, J. M., Disney, M. E., Williams, J. D., and Goels; Z. A. (1969). British Medical fournal, 2, 723.

Squire, J. R. (1950). Clinical Science, 9, 127

Squire, J. R. (1950). Clinical Science, 9, 127.

Stenius, B., and Wide, L. (1969). Lancet, 2, 455. Lyklema, A. W. (1967). fournal of Allergy, 39, 325.
.

Voorhorst, R., Spieksma-Boezeman, M. I. A., and Spieksma, F. T. M. (1964). Allergie und Asthma, 10, 329.

Williams, D. A. (1969). Personal Communication.

\section{Serum Reagins and Leucocyte Response in Patients with House-dust Mite Allergy}

\section{E. S. K. ASSEM, ${ }^{*}$ PH.D., M.R.C.P. ; MONICA K. MCALLEN, $†$ M.D., M.R.C.P.}

$S^{\text {us }}$ ummary: A study was carried out on 26 patients with respiratory allergy' due to the house-dust mite Dermatophagoides pteronyssinus and on 10 non-allergic control subjects using two in-vitro histamine release tests for assessing immediate-type allergy. The first test was on the patients' serum and assessed reaginic (anaphylactic; possibly IgE) antibodies by passive sensitization of normal human lung tissue. The second test was on the patients' leucocytes directly challenged with the mite antigen.

Positive results were obtained in over $90 \%$ of patients, whereas the tests were either negative or very weakly positive in the control subjects. A significant degree of correlation was found between the two tests used, but pronounced differences were observed in a few instances.

Confirmation of the role of $\mathrm{IgE}$ in tissue sensitization was obtained from tests with anti-IgE serum on leucocytes. Positive reactions of patients' leucocytes were also obtained with anti-IgG, anti-IgA, and anti-IgM sera, which would suggest that antibodies belonging to these immunoglobulin classes may also play a part in immediate-type allergic reactions.

* Wellcome Research Fellow, Department of Pharmacology, University College, and Medical Unit, University College Hospital Medical School, London W.C.1.

† Consultant Physician, University College Hospital, London W.C.1.

\section{Introduction}

The role of house-dust mites in respiratory allergy has been the subject of many recent reports (Voorhorst et al., 1967; Maunsell et al., 1968; Pepys et al., 1968; Stenius and Wide, 1969). Dermatophagoides pteronyssinus is now considered to be one of the most important allergens. The study of immediate-type allergy to this mite by in-vitro techniques, which so far has received little attention, is the subject of this report.

Immediate-type allergy (sometimes called atopic or anaphylactic) in man is now generally believed to be mediated by reaginic antibodies which belong mainly to a distinctive class of immunoglobulin (IgE; Bennich et al., 1968). The major manifestations of this allergy are considered to be due to the release, or production and release, of the so-called "pharmacological mediators" such as histamine and slowreacting substance of anaphylaxis. Allergy of this type, therefore, may be detected in vitro by two main groups of tests: (1) measurement of $\operatorname{IgE}$ antibodies specific to the allergen (Wide et al., 1967; Coombs et al., 1968), and (2) elicitation of the specific release by antigen of pharmacological mediators either from cells obtained from the patient (blood leucocytes being the best example) or from normal human or primate tissues passively sensitized by incubation with the patient's serum (Lichtenstein and Osler, 1964; Assem and Schild, 1968). 